\title{
Conceptions of Depression of Muslim Clergy in a Faith-based Organization in South Africa
}

\author{
Prevan Moodley, Noorjehan Joosub, \\ \& Raeesah Shaheen Khotu
}

University of Johannesburg

\section{ABSTRACT}

The biomedical model categorizes certain features of suffering and distress as depression. These same features may receive different conceptualizations within different cultural or religious systems. Islamic approaches to conceptualizing the features of distress, and providing care for persons who display these features may be overlayed on, merged with, or even distinguished from the dominant biomedical model. Clergy play roles as informal mental health helpers, particularly for religious persons. They may also serve as gatekeepers or conduits for facilitating referrals to formal healthcare practitioners. Five clerics at a faith-based organization that serves two small Muslim communities in South Africa were interviewed about their conceptions of suffering that the biomedical model labels as depression. Rooted in their local cultural perspectives, community involvement, religious practice, and help-giving to Muslim persons, social constructionist thematic analysis of interviews with them revealed a nomenclature that contained three main frameworks: (1) depression as a 'real' illness, (2) depression as spiritual destiny, and (3) depression as unallowable sadness. The biomedical view informed their conception of depression as a 'real' illness, and this idea served as the central framework onto which the other two conceptions were hinged. Clergy legitimized certain features of depression as a 'real' illness but indicated that religious illness beliefs cannot be bracketed when serving Muslim individuals. The implication of the study is that mental health practitioners, trained in biomedical ideas, cannot assume that the term 'depression' is understood in the same way within different contexts. Clergy can educate health practitioners about these conceptions to improve caregiving and adherence to biomedical interventions. 
Keywords: Clergy, depression, Islam, qualitative, religious beliefs, South Africa, thematic analysis

Suffering and emotional distress can have various explanations. The particular explanation for a type of suffering may determine its progression and helpseeking options. Since the arrival of biomedicine, the dominant conceptualization directed at suffering has been categorization as various forms of disease. Biomedicine holds master status as a taken-for-granted presence in contemporary society, and it has assumed hegemonic status as a truth. However, social constructionist critiques consider it to be just one master narrative and one version of describing suffering, among many (Lafrance \& McKenzie-Mohr, 2013). Thus, any explanatory model not only serves a diagnostic purpose but also represents a cognitive system that guides both helper and help-seeker toward particular legitimated options for addressing that suffering (Leavey, Loewenthal, \& King, 2016).

As part of this enterprise of assisting individuals who are suffering mentally or emotionally, biomedical logic has been incorporated into the knowledge domains of clinical psychology and psychiatry, with the purpose being the classification of distress so that cure or control can be strategized. This has been part of the modernist and positivist enterprise of science as a system to make society progress. Consequently, traditional systems of conceptualizing suffering and emotional pain have eroded, been displaced, or merged with biomedical aspirations. Objectivist science, however, when overlayed onto subjective or culturally specific experiences, results in stigmatization and, despite the stigma that a mental illness diagnosis can provide, patients and medical professionals have resisted the challenges to the DSM's dominance in categorizing the world (Lafrance \& McKenzie-Mohr, 2013).

Using the catch-all phrase 'mental health', modern societies have created scientific and medical institutions that cater for various forms of human distress. Mental health care is integrated into government to manage populations, but individuals who view the world with traditional, cultural, or religious beliefs may not always seek help from mainstream healthcare systems. With globalization and population mobility diffusing people across geopolitical borders (Leavey et al., 2016), certain groups are considered minorities amid the western, rationalistic, secular, and Cartesian systems, and some of these religious and ethnic minorities may still consult traditional healers, community leaders, or community helpers. In communities with a strong religious following, the systems of care for human suffering include community leaders such as clerics (Ahmed \& Reddy, 2007).

The incorporation of faith-based organizations (FBOs) into mainstream mental healthcare services is thus a complex challenge facing western helpers (Leavey et al., 2016). One complexity is that clergy may hold stigmatiz- 
ing attitudes as was found in a study of Nigerian Muslim and Christian clerics (Igbinomwanhia, James, \& Omoaregba, 2013). If biomedicine is assumed to be the favored model and is integrated into (western) systems that render help, drawing on understandings of clergy's beliefs about suffering and distress could assist mental health practitioners to gain insight into lay, cultural, and religious conceptions of illness; this may contribute to the provision of more culturally sensitive and inclusive services (Padayachee \& Laher, 2014). Access to such appropriate services needs to be facilitated through communication between practitioners and religious leaders (Ali, Milstein, \& Marzuk, 2005). This is particularly the case for Muslims who consult clergy before deciding to consult mainstream helpers (Sabry \& Vohra, 2013); in these circumstances, clergy's beliefs determine referral to mental healthcare facilities (Igbinomwanhia et al., 2013). In a preliminary study based on the rationale of collaboration and consultation in culturally sensitive mental health care and the first known to study imams' recognition of mental illness and consequent referral patterns, Ali and Milstein's (2012) national American survey of 62 imams found that referral patterns included a willingness to refer to mental health clinicians while intending to continue to provide support to a depressed client versus sending the client away for counseling alone. On average, imams considered that a depressed client, who was presented to them in a vignette, needed help if his condition was to improve. Ali and Milstein (2012) recommended increased collaborative practice with health professionals to bring enhanced care, as opposed to training imams in clinical skills only. The implication of this and other studies advocating culturally and religiously appropriate services is that interprofessional collaboration should be favored over training workshops.

Clergy thus play a role as conduits or gatekeepers for how the allopathic model is taken up by religious minority groups. Leavey and colleagues (2016) present a case for studying clergy and community organizations because they are active in patients' help-seeking activities and contribute to the intersubjective and power dynamics that shape explanations of suffering. Because previous research focused on patients' explanations for what has been known as the 'psychiatric', this study instead examined clergy's explanations. When biomedical explanations were used, the clergy's explanations were unicausal; that is, they attributed mental illness to an imbalance of chemicals, rather than using more sophisticated views. Clergy's views were found to reflect the views of the layperson too and did not match a dualistic mind-body explanation because the biomedical and spiritual views of mental illness merged (Leavey et al., 2016).

Explanatory mental health models can shape negativistic attitudes. Igbinomwanhia and colleagues (2013) found that $80 \%$ of Muslim and Christian clerics in Benin City, Edo state, Nigeria, were fearful of having people who were mentally ill live in residential neighborhoods, and $69 \%$ of them endorsed the proposal that mental health centers should be situated outside of residential ar- 
eas. Except for Leavey and colleagues' (2016) study that included seven imams alongside Jewish and Christian clergy in London, and Igbinomwanhia and colleagues (2013) whose survey sample included 15 Islamic clergy alongside 92 Christian clergy, research on the topic of clergy's explanations of mental illness has underrepresented Muslim leadership. A study of clerics at mosques in the United States that used a bigger sample $(\mathrm{N}=62)$ reported that imams were consulted for religious, relationship, marital, and social discrimination problems even though they may not have had counseling training (Ali et al., 2005) but, as this was a quantitative survey, the imam's explanations for mental illness were not accessible. Research on how mental illness has been conceptualized has included both white and African American Christian clergy (Hankerson, Watson, Lukachko, Fullilove, \& Weissman, 2013; Haugk, 1976; Neighbors, Musick, \& Williams, 1998). Ministers of African American megachurches conceptualized depression as a disease, and causative factors were linked to biology, stress, life circumstances, racism, trauma, and identity crises (Hankerson et al., 2013).

Mental illness is conceptualized as biomedical (as opposed to, for example, religious framing of sin). For practicing Muslims, Islam is a prime determinant of cultural norms, beliefs, meaning-making, and social practices (Ahmad \& Harrison, 2007). Questions may be raised about whether such a traditional and perceivably insular system can resist and challenge biomedicine's infiltration, and whether Muslim helpers, who may be consulted for emotional distress, either engage with, encourage, or collaborate with the biomedical system. Dein (2004) recommended a two-way process for all religious personnel in the United Kingdom to be trained to be able to recognize psychiatric disorders and for mental health practitioners to be educated about spiritual meanings of illness and their impact on clinical decisions. Muslim clients may be hesitant to use healthcare practitioners who are perceived to lack integration of Islamic values into psychotherapy (Sabry \& Vohra, 2013), a feature that has been known to characterize many religious groups' unwillingness to engage with psychologists and psychiatrists (Dein, 2004).

Substantiating this complexity for the mental healthcare system, Muslim general practitioners working in a South African Muslim community disclosed that their patients (known to also consult Muslim clergy) were reluctant to seek help from psychiatrists and psychologists because of stigma attached to mental illness (Mohamed-Kaloo \& Laher, 2014). Muslim clergy are thus situated between biomedical and Islamic paradigms that explain and ease suffering and emotional pain. They provide counseling and assist with resolving religious problems associated with health care (Padela, Killawi, Heisler, Demonner, \& Fetters, 2011).

Islam offers a religious explanation for illness. Via the concept of divine predestination, suffering can be considered a means of reparation for sins (AlShahri \& Al-Khenaizan, 2005). The Qur'an describes adversities like illness as 
a test from God, and an individual is not considered responsible for acquiring a mental illness (Ally \& Laher, 2008). Furthermore, Islamic rulings on illness encourage the use of medical treatment for any ailment. Hadith (Sahīh al-Bukhārī Book 76, Hadith 2) reports the Prophet Muhammad to have said, "There is no disease that Allah has created, except that He also has created its treatment".

The value of Islamic beliefs about illness regarding help-seeking behaviors was shown in a qualitative study with women diagnosed with cancer; qualitative data reflects the participants' beliefs that Islamic healers function as moderators or mediums through whom Allah heals diseases (Suhami, Muhamad, \& Krauss, 2016). Other than encouraging Muslims to seek out medical treatment, a Muslim is encouraged to turn to Allah through prayer during distress or extreme sadness (Pridmore \& Pasha, 2004): The significance of prayer during periods of distress is mentioned in the Quran (Yucel, 2010) and the stories of prophets encourage Muslims to use prayer as a path to success over hardship (Sadeghi, 2011; Yucel, 2010).

Islamic conceptions of illness present an alternative to those of mainstream biomedical science. Incorporated into biomedicine, the Diagnostic and Statistical Manual of Mental Disorders- $5^{\text {th }}$ edition (American Psychiatric Association, 2013) enables a common language so that people who are suffering may be assisted within consensually agreed upon and socially legitimated ways. This creates the assumption that mental disorders such as depression exist homogenously across varying cultural systems (Patel, 2001), even though the DSM is critiqued to be modeled on the experiences of middle-class white Americans (Kress, Eriksen, Rayle, \& Ford, 2005). The medicalization of distress began with the third edition of the DSM (Lafrance \& McKenzie-Mohr, 2013), with the effect that it has come to be the "default option for understanding and self-understanding while obscuring other possibilities for meaning and action" (Sutherland et al., 2016, p. 89). The epistemology and ideology of the DSM do not highlight cultural and sociopolitical dimensions of suffering, and isolate the sufferer via the western framework of pathology (Lafrance \& McKenzieMohr, 2013).

Even the biopsychosocial model, called the "offspring" of biomedicine, reinforces biological and reductionistic explanations (Armstrong, 1987, p. 1216). By espousing the biopsychosocial conception of mental illness, clinical psychology, health psychology, and psychiatry do not offer an alternative to biomedicine, compared to critical (political), existential, or experiential approaches (Crossley, 2000). When terms like syndrome, diagnosis, treatment, and symptoms are used, mental problems become constructed as medical diseases (Gray as cited in Crossley, 2000). Rhetoric such as etiology (even if used by a model that claims to incorporate psychosocial factors) maintains biomedical ideology (Ogden, 1997). The DSM is based on classifications that are amenable 
to scientific study, which are constructed from experimental data; it maintains a biomedical ideology through its construction of emotional difficulties and through recommending clinical interventions for that suffering (Lafrance \& McKenzie-Mohr, 2013). Even if the 'social' is claimed to be considered in the biopsychosocial model, such a framework takes a functionalist view of health and illness wherein the cultural and embodied elements are underemphasized (Lyons \& Chamberlain, 2006; Stam, 2004). The 'bio', 'psycho', and 'social' are therefore not balanced and the positivist, biomedical assumptions deny subjectivity that allows for care that is sensitive to cross-cultural variations (Benning, 2015).

Nevertheless, the diagnostic and naming function of the DSM, via the medical assumptions, has allowed relief for many patients diagnosed with depression. Through giving a collection of symptoms a label, the diagnosis validates suffering, particularly because it ascribes a medical reality to something a patient has, rather than blaming the person for something that the person him/ herself has created (Lafrance \& McKenzie-Mohr, 2013). Sufferers are protected in this way: "they are repositioned from 'being a problem' to 'having a problem'. .. . a DSM diagnosis is a powerful resource for individuals in distress as it affords the dual effect of defending their experiences and identities" (Lafrance \& McKenzie-Mohr, 2013, p. 126).

Depression symptoms may, however, present a problem for some Muslims. The key controversial biomedical element is that suicidal ideation is considered a symptom, but according to the Islamic belief system, the act of suicide is a transgression (Rezaeian, 2009). Given this viewpoint, suicidal ideation in itself may often lead to feelings of guilt and shame for a Muslim individual (Sarfraz \& Castle, 2002). The Qur'an explicitly states, "And make not your own hands contribute to your destruction; but do good; for Allah loves those who do good" (Qur'an, 2:195, $8^{\text {th }}$ Abdullah Yusuf Ali revised Amana edition). The Qur'an also states, "Nor kill or destroy yourselves: for verily Allah has been to you Most Merciful!" (Qur'an, 4:29). Relatedly, if a person who is not capable of making decisions objectively commits suicide, that person is considered not accountable, for it is God who judges the individual's actions, and this can assuage the guilt for families of patients who have been severely mentally ill (Sabry \& Vohra, 2013).

A further problem with the biomedical conception of depression is the underlying ideology that implies that the features represent a universal condition. The everyday, colloquial use of the word 'depression' is often associated with feelings of unhappiness and grief. This ordinary usage does not imply that clinical criteria are being used to describe an individual's complaint or suffering; instead, an individual may conceptualize and experience symptoms using culturally relevant explanations. Depression, unhappiness, and grief may be 
understood in some cultural contexts as normal responses to adversity, loss, and severe social or personal threats (Abdul Kadir \& Bifulco, 2010).

Even though mental illness conceptualizations across cultures have been acknowledged as having the potential to be controversial, depression in particular may have meanings and conceptualizations that need interrogation to inform better care. Because clergy are the gatekeepers for the constructions of illness in traditional Islamic communities, this study focused on clergy. Clergy may set the tone, as well as choose and facilitate the routes of access to care, and they shape the construction of what they or their congregants may call 'depression. This study aimed to explore how Muslim clergy conceptualize, intervene in, and advise individuals living with what they may consider mental illness and, particularly, depression. In other words, we sought to discover their conceptions of mental illness, with a focus on depression.

The DSM represents the dominant model for particular behavioral, emotional, and psychological features that coalesce to become known as depression. The 'master status' of the DSM has persisted despite decades of critiques against it, particularly in terms of its individualistic and westernized ideology. Lafrance and McKenzie-Mohr (2013) argue that such top-down processes do not account for the staying power of universalist discourse, because bottom-up uptake of the discourse is an active process whereby people who are suffering find those explanations useful. Focusing on clergy, this study explores how one particular bottom-up process can occur when they facilitate help for people with depression.

Differences in lay explanations for depression have been studied in western and nonwestern contexts. Hansson, Chotai, and Bodlund (2010) noted in a Swedish study that explanations for the cause of depression focused on life stressors. In Iran, Turks, Kurds, and Iranians perceived the cause of depression to be either internal factors (e.g., emotions) or difficult external events (e.g., family conflict; Dejman et al., 2010). A study of Indian women in a low socioeconomic area indicated that almost half of the participants reported suicidal ideation, with some attempting suicide, a marker of depression (Pereira et al., 2007). The women attributed their feelings to difficulties in finances, children's wellbeing, health, excessive domestic responsibilities, and family members' problems (Pereira et al., 2007). Despite the lack of biomedical insight, most of the participants had consulted medical professionals for their reproductive and somatic complaints (Pereira et al., 2007). Thus, depression may be understood by lay individuals as an expected reaction to social and personal problems (Kangas, 2009). The lay concepts of depression are thus understood best from within the social worlds that provide meaning to their symptoms.

The biomedical concept of depression may also not be recognized in a community's understanding of illness, because the word 'depression' may hold 
little cultural meaning or value (Selim, 2010). The differences in help-seeking behaviors and adherence to treatment illustrate the importance of lay, cultural, and religious conceptualizations. For example, cultural beliefs in Norway were found to influence help-seeking behavior-individuals preferred self-help interventions such as rest, exercise, and spiritual activities over treatment offered by mental healthcare professionals (Erdal et al., 2011). Asian women suffering from depression used coping strategies that included prayer, talking, crying, and self-harm (Hussain \& Cochrane, 2002). Similar findings indicated that Iranian women found solace in avenues such as prayer, help from family and friends, and positive thinking (Dejman et al., 2009). Iranian women viewed medication and consulting with psychologists as last resorts, primarily due to the stigma associated with accessing psychiatric intervention (Dejman et al., 2009).

The choice to use private coping strategies along with a reluctance to access mental health practitioners can be understood to be influenced by stigma (Cinnirella \& Loewenthal, 1999). Dejman and colleagues (2009) call for depression to be publicized as a treatable medical illness to legitimize help-seeking. Family and friends could help patients seek out care; yet, patients families and friends could still undermine and discourage treatment and recovery because of negative messages about depression (Garcia et al., 2012). Many participants in Garcia and colleagues' (2012) study said they were labeled, judged, lectured to, and rejected by family and friends when discussing depression. In this sense, social networks may hinder an individual from disclosing symptoms to mental healthcare providers and from adhering to treatment. It could be that depression, when categorized as a mental illness, gets associated with psychotic disorders, which explained the majority of Nigerian Christian and Muslim clergy believing that a person who is mentally ill can be differentiated from 'normal' people (Igbinomwanhia et al., 2013). Despite the stigma, clergy will be faced with congregants who present with depression as a reason for the visit; Ali and colleagues (2005) found $87 \%$ of imam participants in their survey reporting that sadness or depression was the reason for congregant visits sometimes, often, or very often.

Scrutton (2015) offers an overall framework that summarizes the models. Scrutton's textual analysis of conceptualizations of depression addressed three models of depression: medical, moral, and social; of the three, medical and moral models locate the problem within the person and remove hope (Scrutton, 2015). Medical models, because of their essentialism, restrict expansion of purpose or utility, such as depression representing spiritual transformation (Scrutton, 2015). The moralizing model, as illustrated in Christian self-help books and websites, specifies that mental illness is a sign of living a life against God's prescriptions. Moralizing models do not acknowledge social causes of depression, thus relinquishing the church's responsibility from combatting fac- 
tors of depression such as oppression and social injustice. Conceptualizations, therefore, should move away from depression as an individual sin because it can be caused by social sins such as discrimination, poverty, violence, and minority status (Scrutton, 2015).

\section{Methods}

\section{Sample and Recruitment}

We selected a national FBO, the Jamiatul Ulama South Africa, to recruit clergy. The organization's website (http://www.jmtsa.co.za) indicates it has been operating for 95 years (as of 2018) and its core purpose is directed at "[r]ecognised leadership, uniting, developing, guiding and representing Muslims". Made up of multiple agencies, the FBO has a membership of over 900 Islamic scholars who offer religious guidance and advice to Muslim communities in branches across three provinces in South Africa. The FBO's social department, which offers support for marital problems, is supplemented by a community project that is a registered nongovernmental organization (NGO); this NGO provides psychosocial community services (e.g., counseling, support groups, telephone helplines), and staff and volunteers involved in counseling have an academic background. In addition to the social department, the FBO offers religious education and support services (e.g., publishing of books, welfare provision and financial assistance funded by charity, the resolving of queries relating to religious best practices, and educational workshops, etc.; http://www.jmtsa.co.za).

Table 1. Sample Details

\begin{tabular}{ll}
\hline Race & Indian \\
\hline Age (Range) & $30-69$ \\
No. of clergy recruited & 7 \\
No. of clergy interviewed & 5 \\
No. of moulanas & 4 \\
No. of muftis & 1 \\
No. of FBO branches at recruitment & 2 \\
\hline
\end{tabular}

A study coauthor telephoned the head of the FBO's social department to explain the study and discuss the possibility of recruitment of clergy. This head, a mufti ${ }^{1}$ who oversaw the operations in that department, informed resident clergy of the research, got permission to give their contact details to the researcher, received their contact details, and then communicated to the clergy that they will be contacted for an interview. Clergy were required to have direct

1. mufti: A male Muslim legal expert who has studied further than a moulana. Unlike a moulana, a mufti is able to interpret verses in the Qur'an and determine Islamic laws (Moj, 2015). 
pastoral involvement in the community. All eligible clergy were contacted; of the seven clergy members contacted, five expressed interest in study participation. The two who refused participation were a moulana ${ }^{2}$ whose reason was that he worked in a sector unrelated to the social program, and a mufti who could not fit the interview into his schedule. The study coauthor met with each willing cleric and explained the study. If an interview was considered acceptable, it was set up. Prior to the interview, the study was explained again. Each cleric signed a consent form and was informed he could withdraw participation at any time. Each cleric was interviewed either in his office or another vacant room at a FBO branch. They were not paid for their participation. Table 1 above contains details of the sample.

\section{Procedures}

Clergy participated in semistructured interviews (see Table 2) conducted in English and which lasted between 45 and 60 minutes. The Muslim coresearcher who conducted all the pre-interview communications also interviewed the clergy, and resided in the same district community as the clergy at the time of the interview. She engaged actively with respondents in the interview, approaching it as a conversation within an Islamic hermeneutic. The audiorecorded and transcribed interviews were analyzed using thematic analysis (Braun \& Clarke, 2006). Each participant was assigned a code number to ensure anonymity in the transcripts.

Thematic analysis (Braun \& Clarke, 2006) was compatible with the exploratory aim of the research. Thematic analysis allows an epistemological position to interpret data (Attride-Sterling, 2001). Our position was social constructionist to enable an analysis of the constructions of individuals within specific social contexts. Individuals do not merely passively internalize external cultural forces; rather, individuals use numerous social constructs to make sense of their experiences throughout their lives (Frosh, 2003; Raskin, 2002). The combined use of thematic analysis and the social constructionist position was aligned with the research goal to explore a social phenomenon that had received little theoretical attention.

The inductive approach was aligned with Braun and Clarke's (2006) social constructionist version of thematic analysis. The interview data were reread for familiarity. Manual coding was used to identify trends. Reading the data line by line enabled codes to be written alongside relevant data excerpts. Codes were sorted into overarching themes, each of which was identified and given an explanatory title. We often recategorized codes to ensure that the themes represented the data convincingly. We also reread the original data to include

2. moulana: A title given to a Muslim male who has "completed a course of studies on Islamic education at the tertiary level" (Khan, n.d.). 
Table 2. Interview Guide

What is the Jamiatul Ulama?

How do you become a board member of the Jamiatul Ulama?

What is your role in the Jamiatul Ulama?

What is the purpose of the Jamiatul Ulama in the Muslim community?

What services are offered to individuals in the Muslim community?

What mental health services are offered in the Jamiatul Ulama?

How do individuals contact the Jamiatul Ulama for consultation?

Why do individuals consult the Jamiatul Ulama?

What is the understanding of illness in Islam?

What is the understanding of mental illness in Islam?

What is the understanding of depression in the Qur'an and Hadith?

Does clinical depression exist in Islam? If not, Why?

How do you explain physical symptoms as a result of clinical depression?

Is depression recognized as a mental illness or just as a feeling of sadness?

What causes depression?

Why does Al-Qarni (in the book Don't be sad*) state that all Muslims are susceptible to depression but a true believer is not?

Is a Muslim living with clinical depression considered a weak believer?

What advice does the Jamiatul Ulama offer to individuals living with depression?

What treatment is available for Muslims living with depression?

Is psychotherapeutic intervention allowed to treat depression?

Is a Muslim allowed to take antidepressants for treating depression?

Does the Jamiatul Ulama collaborate with mental healthcare practitioners?

Do Muslims living with depression and receiving mental healthcare treatment consult the

Jamiatul Ulama for help with managing their symptoms of depression?

Do you feel that individuals living with depression are stigmatized in the Muslim

community?

* Al-Qarni, A. I. A. (2003). Don’t be sad. (F. I. M. Shafeeq. Trans.). Riyadh, Saudi Arabia: International Islamic Publishing House. (Original work published 2002).

any information missed during the initial coding. This step ensured that the themes related to each other, as well as the data set to logically explain the different conditions that contributed toward clerics' conceptions of depression. Extracts were then used to substantiate the theme accompanied by a detailed explanation about its relevance to the research question.

To ensure transparency and to interrogate potential bias brought about by being a member of the same minority community as the clergy, the interviewer kept a reflection journal to ensure reflexivity, particularly during data interpretation. Reflexivity is the process of examining how researchers' intersubjective thoughts about the topic may interfere with or even transform the research outcomes completely (Wertz et al., 2011). The journal ensured reflexivity by constantly reminding the primary interpreter of her positions to allow the interviewee to become the sole narrator (Wertz et al., 2011). Other steps were taken to ensure trustworthiness. Two coresearchers read the interview data, established their own codes, and all three then reached consensus about the interpretations. Furthermore, the study ensured that at least one coresearcher 
was not Muslim, so that Islamic ideas and values were not taken for granted in data analysis.

\section{Results}

The analysis revealed three different conceptualizations of depression, or more specifically mental illness, because depression, as a term for a disorder, is a biomedical rather than cultural or religious construction. The clergy did not structure their narratives and thinking into the different types of depression, but this nomenclature arose from the researchers' engagements with the data. The three themes were: (1) depression as a 'real' illness, (2) depression as spiritual destiny, and (3) depression as unallowable sadness.

"It is also a real sickness as other sickness": Depression as a "real" illness

The clergy expressed biomedical understandings of depression:

It is an illness that has to be treated medically at times; especially certain types of medication may be needed to calm a person down. (M1)

There are these conditions that people do suffer from, and I think one is clinical depression which is a complete medical condition which needs treatment in which ever form. (M3)

I have also come to realize depression is not just the definition of happiness or sadness; it is also a real sickness as other sickness. (M4)

In line with the idea that depression is 'real', clergy mentioned chemical imbalance as etiology of depression and, consequently, the necessity for medication:

If we go to a mental institute, people there have chemical imbalance; they can be treated if they take their medication. (M1)

There is a mental imbalance and because of that mental imbalance, you do need to go to a doctor. (M4)

Nabi Kareem [Honorable Prophet]'s very famous saying, 'that for every sickness, there is a cure so seek out that cure'. So I don't think the two are contradictory. I think both are perhaps complementing one another. (M4) 
When they took their medication, it made a big difference in their lives. (M4)

M4 mentioned that the Prophet Muhammad encouraged Muslims to seek out cures or medicine for their ailments, therefore consulting a medical practitioner is a religious recommendation. Another emphasis was on the requirement that the community be educated about medical treatment for depression. Therefore, unlike the clergy in Igbinomwanhia and colleagues' (2013) study in Nigeria, the clergy in our study were aware of, and resisted, the stigmatization that accompanied a psychiatric diagnosis. This finding is similar to another South African study (Mohamed-Kaloo \& Laher, 2014) where medical practitioners expressed the view that Muslim patients are reluctant to seek assistance from mental healthcare practitioners due to the associated stigma. The following quotes illustrate the clergy's advocacy for mental health education within the Muslim community and, particularly, for mental illness to be managed by mental healthcare practitioners:

People don't know it's a condition that needs treatment they just become very irritable, they think they stubborn, and they just leave them. (M3)

Muslim people do tend to shy away from going to a psychologist or psychiatrist because of the stigma attached to it. However, I have come to realize in many ways, through family, when people become very depressed, together with giving advice that we would normally give, perhaps medical advice would also be needed. (M4)

Given their acknowledgement of the role of medical practitioners, the clergy accepted that management goes beyond their own supportive roles, thus they needed to make appropriate referrals. Even though all the clerics acknowledged that faith is central to the understanding and management of depression, they seemed to surrender their religious ideology to the view that 'real' depression requires medical intervention:

They do not come to accept it unless now they go to someone that advise them to go psychologist and psychiatrist and sit down and explain to them. Then, maybe they will understand to some extent what depression is. (M2)

We advise them to go for medical treatment to psychiatrist or psychologist because we are not qualified in that area. (M3) 
Will refer psychologist and psychiatrist: We have a list if we need to refer to them as well if we need. (M5)

What seemed to inform the readiness to accept the biomedical model of care was the counseling training they received. Given this move toward making depression 'real', religious intervention was undermined. Clergy believed that individuals who were perceived to have 'real' depression would not benefit from their pastoral help, and they referred those persons to the FBO's counseling center. They explained the relevance of their training in adopting a biomedical conception of depression:

What we know about depression is from experience and basic counseling training. (M3)

Once we see that we have seen one or two that are very depressed, I directed them to the Care-line and the relevant medical authorities. Although we have the counseling skills, we realize that we don't have the skills, especially to take a person who has long-term depression out of it. (M3)

I know about the difference between sadness and depression because of my counseling training and the counseling itself and from experience. (M5)

This might be considered appropriate collaboration, but the clergy's knowledge seemed limited to the identification of the general depressive symptoms listed in the psychiatric diagnostic manual. They did not distinguish different types of mood disorders, and they used the word 'depression' as an umbrella term to describe a collection of particular features (see Table 3). Still, they recognized the symptoms of depression, showing that their ideas were not lay knowledge but ideas they had learned. Table 3 shows how their understandings of depression overlapped with symptoms mentioned in the DSM-5.

The very notion of educating clergy about mental disorders represents the governance of mainstream medical knowledge into traditional and cultural domains. Framed as 'collaboration', the imparting of psychiatric knowledge to clergy is about modern biomedical intrusion into the traditional Islamic system. Training was cited to have enabled the clergy to identify biomedical symptoms of depression. This differs from a U.S. study that found that a sample of Muslim clergy, compared to clergy in other faith groups, were the least likely to have formal and comprehensive training to attend to the mental health needs of congregants (Ali et al., 2005). In contrast to the clergy in our study, it is possible that, because the imams interviewed in Ali and colleagues' (2005) study were based in mosques, rather than an organization that housed both secular and traditional services, those particular clergy had less access to mental health 
Table 3. Clergy's Mention of Features That Align with DSM-5 Symptoms

DSM-5 Common features of depressive disorders (APA, 2013, p. 125)

"Depressed mood most of the day, nearly every | day, as indicated by either subjective report ... . or... observation made by others".

"Markedly diminished interest or pleasure in all, or almost all, activities most of the day, nearly every day"

“Feelings of worthlessness or excessive or inappropriate guilt."

“Insomnia or hyper-insomnia nearly every day."

"Recurrent thoughts of death (not just fear of dying), recurrent suicidal ideation without a specific plan, or a suicide attempt or a specific plan for committing suicide".
Symptoms of depression identified by participants

Depression for me is something we fall in, it is like a slumber that we cannot come out of ... . we do not see the light, we give up totally that leads to clinical depression. (M5)

Not having any hope, not seeing any light, not seeing any future, and the more serious the circumstance or the challenge is the less hopeful they then become. (M3)

You could see from his demeanor he was completely down, he did not smile; you could not get him to look at the positive. As much as I tried to give him some hope, some confidence, to make him feel good about himself he just wasn't interested at all. (M3)

You angry because you cannot find help. You feel helpless; the basis of depression is helplessness. That anger sometimes confines you to feel helpless although there is help just in front of you do not recognize it. (M1)

Depression is when people are completely demotivated, lethargic, not motivated to do anything, which normally people would do something which people would not be able to do it. (M4)

When you depressed you try to stay away from people, you do not want to do anything. (M2)

They become so down that they not interested in doing anything ... She stopped performing salah, she stopped reading Quran, yet before she was very punctual. (M3)

Your mind only focuses on all the mistakes, where you have gone wrong ... Your mind only works on the negative and it does not give you a chance on work positives. (M2)

A person has a low self-esteem sometimes and they feel responsible for their own circumstance or they do not feel they worth it and that their life is meant to be that way so they just suffer within. (M3)

You are not able to sleep because in your sleep that depression is working on you. (M2)

You find an increase in suicide rate even in our Muslim community and a lot of it stems from depression. (M1)

Depression makes you feel down in your heart, you lose your self-esteem, and you feel you are worthless, like you cannot do anything, if this worsens you may become suicidal. (M2)

We had a man whose wife ran away with another man and she ran away taking his baby with him. Eventually the wife came back but he committed suicide. That would be depression for me, she came back, he wanted his daughter back but he could not overcome the grief and the hurt. (M5) 
education. Also, compared to the Nigerian study (Igbinomwanhia et al., 2013), which recommended that clergy be educated about mental disorders, the differences between them, and associated myths, the clergy in our study seemed knowledgeable about symptomatology of depression.

Clergy in our study may be informed about mainstream conceptions and mental health interventions compared to other studies (e.g., Igbinomwanhia et al., 2013) because they reported having received input from a psychologist:

The training that we have is at the Islamic Care-line. They run a training once a year. So we have done it under them. There is a qualified psychologist who has been doing the training for many many years. (M3)

The Care-line arranges people to come from outside and train us. We always do refreshers and, when we have time, we go for new courses. And, we have debriefing once a week or once a month, depending on the course. This is done by psychologists, and they advise on the case and any difficulty experienced during the cases. (M5)

The collaboration with a psychologist in our study seemed to have been a welcomed and expected activity for the clergy. Furthermore, lay explanatory models of depression, as was the case with persons with higher education in Iran, accommodate consultations with psychologists (Dejman et al., 2010).

Thus, with reference to their knowledge about chemical etiology and their counseling training, this theme showed that clergy constructed depressive features as a disease. Many African American megachurch clergy also conceptualized the cause of depression to be biochemical factors, but without the additional spiritual etiology (Hankerson et al., 2013) that characterized the conceptions of clergy in our study.

This theme shows that depression was reified as a medical illness and (mis) understood to be amenable only to pharmacological treatment. When probed, clerics expressed that congregants perceivably did not wish to consult mental health practitioners for depression because of the belief that practitioners lack understanding about Islamic worldviews. In their opinion, this prevented the Muslim community from accessing formal mental health care:

What we find is that people go, and we hear this complaint very often. We go to a psychologist for counseling, but the psychologist does not understand us. It comes up maybe 90 percent of the time. It's our cultural background and the value we place on certain aspects of our life; it is unacceptable to use un-Islamic means to assist individuals ... you can assist a Muslim but it must be within Islamic means. (M3) 
I think it would be better because they might be able to understand the challenges, the stigma; they would be able to understand the things called jadoo and black magic, and why taweez $z^{3}$ play an important role, maybe others may not be able to fathom those situations. (M4)

Thus, although depression may be recognized as a 'real' illness that requires biomedical intervention, clerics were of the opinion that Muslim patients needed religious beliefs to be integrated into their mainstream treatment.

One particular feature of depression that interfaced with the notion of the disorder being 'real' related to how the clergy conceived of suicide and suicidal ideation. From their conception of depression as being caused by a chemical imbalance beyond the person's control, the clergy also conceived of suicide as an act beyond rational control. Suicide is considered a sin in Islam, but the participants believed that a person who commits suicide should not be held accountable for her or his actions:

Maybe worldly wise, the people will judge you according to what you have done; but I think Allah will have mercy upon you because he knows exactly what went through. (M2)

So we can't make a judgment, if a person takes their own life; we don't know what they going through, so Islam teaches us very often that we shouldn't be judgmental. (M3)

Suicide is forbidden, according to the Qur'an (Sabry \& Vohra, 2013). However, it is also accepted among Muslim scholars that those with serious mental illness will not be held accountable for their actions, and forgiveness is therefore possible (Vasegh, 2011).

Participant views expressed an overwhelming presence of biomedical discourse, due perhaps to their exposure to counseling training, but also to the dominance of this discourse in society at large. Although this allows them to understand that depression is not something a person can control, it also leads them to undermine their own indigenous knowledge about mental illness in favor of the dominant, accepted, biomedical discourse. The biomedical presence was so convincing that they felt they did not have the expertise to help and resorted to sending seekers away to the counseling NGO affiliated to their social department. This referral choice is in stark contrast to imams in Ali and Milstein's (2012) study who, on average, responded they would probably or definitely refer a hypothetical depressed person to a mental health practitioner while still continuing to support the help-seeker

3. taweez: In South Asian culture, an amulet worn for superstitious protection from the evil eye or black magic given by a traditional healer (Dwairy, 2006). 
themselves. Overall, this theme depicts the ways in which the biomedical paradigm and the DSM master narrative are legitimized and reinforced (Lafrance $\&$ McKenzie-Mohr, 2013), and quite actively so, by spiritual leaders in a South African Muslim community.

\section{'It was written for you": Depression as spiritual destiny}

Drawing on the idea of taqdeer ${ }^{4}$ or predestination, clergy considered their pastoral role as being to assist Muslims to cope with and accept life's difficulties. Depression was conceptualized as one of life's difficulties over which the individual had no control. In this sense, it was considered to be part of people's destiny and could be a test from God. Clergy reported they used this idea in their pastoral counseling sessions to provide individuals with religious comfort for their distress. This involved encouraging congregants to use their religious beliefs to accept suffering that accompanies medical depression. Even if the cause of depression is purported to be medical, such an etiology must still be subsumed by the concept of taqdeer:

The coming of any illness is understood as taqdeer. Thereafter, you place your faith in Allah and use whatever means you can to heal yourself. (M1)

Many things are beyond our control, we have to make the effort, but then you must leave everything in the hands of Allah, in his trust. (M1)

Allah has mentioned in the Qur'an: Whatever difficult times are upon you, Allah has already written about it. That is your taqdeer ... be it a sickness or anxiety. (M2)

This theme is informed by the Islamic view of predestination. Muslims believe that both suffering and comfort result from God's will (Al-Shahri \& Al-Khanizan, 2005). According to this view, believers are exhorted not only to find cures for their ailments (as in the theme of being a 'real' illness), but also to engage with spiritual thinking to inform the suffering associated with illness and, further, to even prevent depression, specifically:

For a person not to move from the point of sadness to depression, they need the belief that whatever has happened has been predestined; so, whatever happens ... it is decided by Allah, but it is only to test your belief in Him. (M3)

4. taqdeer: predestination; the idea that God has predetermined life events and circumstances. (Salem, 2014) 
The idea that God's will and plan is superior to one's own is echoed in both the Bible and the Qur'an (Vasegh, 2011). Believers of Abrahamic faiths are encouraged to accept life's difficulties as inevitable and as a way of strengthening their belief. Further, some Qur'an and Bible verses indicate that there is a benefit to suffering as God rewards those who are patient through adversities.

According to Dein (2004), clergy are often confronted with questions pertaining to God's reason for choosing the individual to suffer, as posed by the question, "Why me?" Similarly, three clergy stated that individuals seeking help often asked the question, "Why me?":

When you lose that hope and feel no one can help you ... it is very difficult to understand that you receive help from Allah that you cannot see. At this point, they always ask, 'Why me, what did I do?' (M5)

They direct all their anger toward Allah and say, 'If Allah does this to me why should I worship him? ... They actually stop all obligatory duties toward Allah and feel that he is not a merciful creator. (M3)

Verses from the Quran indicate that those who are going through difficulties are favored by God, therefore they should not feel despondent because God will bring relief and reward (Vasegh, 2011). This was echoed by one of the participants:

Sometimes Allah brings about difficulty as a test, through the means of the test Allah elevates your status. (M4)

Because of the assumption that mental suffering is destined, clergy reported that they integrated Islamic values and beliefs with mainstream counseling techniques during counseling sessions. Clergy reported that they commonly advised depressed individuals to seek solace in prayer:

The only way you're going to get help is from Allah. So you need to try your utmost to connect yourself with Allah. That means salah ${ }^{5}$; remember Allah when you make dua ... that maybe helps you to console yourself in this situation you are going through. (M2)

Clergy believed that by focusing on the positive aspects of life, individuals

5. salah: "an Arabic word to mean a spiritual relationship and communication between the creature and his Creator. Salah is one of the five pillars of Islam. A special communication (Salah) is to take place five times a day for a Muslim" ("Key to Islamic concepts", n.d.). Salah is the physical form of prayer, resembling yoga postures; dua are verbal supplications, silent or spoken aloud, either during salah or outside of it. 
will be able to counter the effects of depression; the Qur'an encourages gratitude for God's favors (Sabry \& Vohra, 2011). With depression being conceived of as part of an individual's spiritual destiny, clergy were able to assist congregants from a pastorally congruent base. This did not work against the idea of depression being a "real" illness because disease was considered to come from God; disease was predestined as one test for any one individual. Interspersed in this way, the clergy seemed to have been empowered as community representatives of caregiving. They were able to take an active role in the process of assisting their congregants in a religiously coherent manner.

"If you are sad for worldly reasons it is not approved of in Islam": Depression as unallowable sadness

Depression was talked about in terms of what it is not, drawing a distinction between what is acceptable and what is not acceptable. When depression was conceptualized as 'real', it was considered acceptable and, when an individual presented with this type, the clergy considered this type of depression not easily susceptible to moral judgement. In other words, when the presentation was not reified as an object worthy of care (as in everyday sadness), depression was considered to be unacceptable. In this theme, another conception, a condition of unallowable sadness, could be differentiated from the 'real' version of the condition. This type of depression was unallowable and therefore transgressive because even though it may present itself with features of 'real' depression, it was associated with certain (everyday) conditions. Here, the conception can be defined as distress rooted in everyday life difficulties. This is not 'real' depression, and the clergy argued for this form as having the presentation of excessive sadness that follows from difficult life events. This is not an unusual conceptualization because studies (Dejman et al., 2010; Pereira et al., 2007) have illustrated that different cultural groups consider depressive symptoms to be reactions to social stressors. However, this theme in this study had a moral slant. The Islamic frame constituted this type of depression as unallowable, and clergy identified recurring life situations that could contribute to excessive sadness (unallowable depression) in congregants.

To establish what can be considered legitimate depression (a state beyond ordinary sadness), the clergy offered conceptualizations about what should not be considered depression (unallowable sadness). In other words, they had to refer to an Islamic benchmark to distinguish between what was allowable and real versus what was unallowable. Referring to Islamic texts that frame such a conception, both the Qur'an and hadith have defined parameters for acceptable and unacceptable reasons for sadness. M3 drew on the example of the Prophet Muhammad crying to demonstrate that certain sadness is acceptable in Islam (and, by implication, what is not acceptable): 
The Prophet himself felt sad when his son passed away, he even cried ... The companions around him asked why he cried, so he said it's a natural emotion. Allah places in the heart of people that are merciful. Crying during difficult circumstances shows your heart is soft and there is nothing wrong, it is acceptable. (M3)

Although sadness is an accepted response to certain situations, as in the preceding case involving the Prophet Muhammad, excessive sadness was considered to be frowned upon in Islam: M5 explained that though the Prophet experienced sadness, he did not allow it to progress into a depression and to become negligent. He added:

So depression will happen. You will go into a slumber. You will be sad, but your belief in Allah will help you to come out of it, because you know there is something stronger out there for you. (M5)

To communicate this distinction, clergy gave examples. In the case of the unallowable variety, either the community or the clergy - motivated by Islamic values of care and community-were reported to be able to help this type of 'depression' (i.e., unallowable sadness). Everyday life situations that contributed to this conception of unallowable sadness, as reported by the clergy, included familial disruptions, marital problems, financial troubles, and physical disabilities (see Table 4). Examples of marital difficulty cases included a husband marrying a second wife, or an instance of gender-based violence. In another familial disruption, one of the clergy narrated the story of a young boy who lost his father to hijacking. This led to financial difficulties, and by the time the boy consulted the clergy, the boy "completely failed school, could not study, read salah, and does not do anything, he says he can't". When conceptualized as excessive sadness resulting from these difficult life events, the condition differs from explanations of depression either as a medical illness or as spiritual destiny.

The conception of life stressors causing depression was found in Hansson and colleagues' (2010) study where patients cited work-related stress, personality, and family problems as main causes of depression; but what is novel in our study is the distinctly moral tone that this cause is not acceptable. This may be attributed to the assumption, particularly in a many-pronged FBO, that the clerics and community in our study can be considered to provide adequate intervention for distress resulting from life stressors.

Besides the preceding examples, another example of a life stressor stood out: A form of sadness rooted in materialist or "worldly reasons" where the cleric referred to the situation of material comparisons: 
Table 4. Conceptions of Depression as Unallowable Sadness: Everyday Stressors

Difficult life situations

Familial disruptions: Depression may occur in youth after the loss of a parent. Major changes in family life compounded with financial difficulties result in distressed youth giving up on life and religious obligations. Youth are offered spiritual mentorship by clergy who assist them to overcome these difficulties.

Marital problems: Due to the sanctity of marriage within the Muslim community, sharia laws are used to govern marriage. The deviation away from the Prophet Muhammad's (PBUH) teachings about marriage was perceived by clergy to contribute towards the increase of marital problems in Muslim communities. When confronted with relationship difficulties, individuals often remain in unfulfilling relationships, and this results in them feeling helpless and depressed. Clergy may therefore often counsel to couples to alleviate marital disputes.

Finances: Depression results from unrealistic financial expectations, seeking happiness in material possessions, or the lack of financial resources to meet basic needs. The more community members attempt to find contentment in material possessions, the more likely it is for them to experience depression as they are not able to find meaning and purpose.

Physical disability: Individuals who are not able to take care of themselves have been understood to experience increased depression.
Quotes of depression resulting from everyday stressors

A young boy came here for counseling. His father was coming home from work; he had a punctured tire, was hijacked and shot. He passed away. They had a shop, the mother could not run the shop and it went bankrupt... After that he completely failed school, could not study, read salah and does not do anything, he says he can't. (M5)

A women came in here regarding her husband taking a second wife ... she had a skin disease and felt that her husband decided to take a second wife because of her condition. ... After counseling with us, the husband realized it was not worth taking a second wife because of the pain and hurt it caused her.... We got them to put it behind them but I think she was in a depression during that period. (M1)

In talaq [divorce] issues where a girl is really being battered. Where she loses her dignity because she is abused physically and sexually. She feels there is no hope.... We step in and end the marriage when the man will not release his wife... when a women like this receives a talaq and gets out of a bad marriage she turns a new leaf and feels Allah gave her a chance to start again. (M5)

I do not know why there is so much depression compared to $30,40,50$ years ago ... it happens that the more material prosperity there is the more depression ... because materialism by its very nature is not geared to provide contentment and tranquillity ... unrealistic expectations in life could lead to depression or lead to symptoms of depression. (M4)

There was a person in extreme financial difficulty. . . a few months they had no income ... he approached me for an Islamic point of view on how we could assist him and he said that because of his problem he was considering suicide.... I think what frightened him was that he was accessing internet sites that describes how to commit suicide ... the fortunate thing was that we could help; the community took responsibility and saved his house and took care of his basic needs ... there is a huge difference in where he was and where he is now. (M3)

Children who are blind or have other disabilities always find themselves in a state of depression because they feel inadequate; they feel that they depend on too many people. (M1) 
If you are sad for worldly reasons, it is not approved in Islam ... it depends on what has led to your sadness; if you are sad that you don't have money to the degree that your neighbor has, that is a clear-cut injunction in the Quran that do not look at envy what Allah has granted someone else, you don't know what situation that person is in. Why should you look at someone's wealth and look sad, so it depends on the reason for sadness. I feel that people have very great expectations with regard to wealth being the hub of goodness. "If I get 20,000, 50,000 more, I'd be happy", people do have this tendency to equate material things with happiness and that might not necessarily be the case. The elder you become, there is an inclination toward worldly and material things. (M4)

The same cleric cautioned that the pursuit of material wealth should not allow congregants to become depressed and, as illustrated in the preceding extract, not transform envy into depression. This was a key distinction for M4 who, when asked if the word 'depression' appears in the Quran, primarily conceptualized depression as the state that occurs during the unrealistic pursuit of "material prosperity":

Not per say as how we understand it, but I suppose in many ways there is indication to it, that to not make material prosperity the bases of your happiness, also look at the remembrance of Allah. I personally feel strongly on this, just as you have material need for your existence you also have a spiritual need for your existence. Also, there is a spiritual need you have to fulfil just as how you fulfil material needs, just as you need water and drink to sustain you. You also need the remembrance of All Mighty Allah to sustain your spiritual need, without which you will have a void in your life, and that void sometimes does manifest itself in various ways, perhaps it might manifest itself in itself in unrealistic expectation of life that of course could lead to depression or could lead to symptoms of depression. (M4)

The cleric here conceptualizes depression as a void caused by either unrealistic expectations regarding material wealth or the spiritual void that ensues if material wealth, rather than spiritual wealth, is sought after as a source of happiness.

Within the notion that depression results from life difficulties, clergy mentioned that once the difficulty is resolved the individual no longer displays depressive symptoms. Thus, the theme of unallowable depression can be regarded as displaying the diagnostic features of adjustment disorders in DSM-5 (APA, 2013). Adjustment disorders can be described as emotional or behavioral responses to stressors in daily life (APA, 2013). Persons with this type of depression were regarded by clergy as requiring assistance in the form of financial assistance or support received through pastoral counseling. The clergy's FBO 
provides assistance through $z a k a h^{6}$ or by using funds from the zakah fund to those individuals presenting with 'depression' due to financial difficulties. The pastoral counseling for these difficulties focuses on teaching an individual to find positive meaning within life's difficulties. Clerics drew from the Qur'an and prophetic teachings to explain how contentment can be instilled in individuals facing 'depression' resulting from life difficulties:

The Prophet Muhammad said there are positives and negatives in life, the men that tend to ponder on the negatives of life will be sad no matter what he does, but if he looks at the positive of his life he will be happy no matter how many difficulties he goes through. (M1)

In this sense, the teachings discourage rumination, and Muslim individuals who experience depression because of life difficulties should change their focus. By focusing on the positive aspects of life, individuals will not experience this morally transgressive type of depression. In this conception, an individual should not allow sadness to become excessive and overwhelming.

The overlapping of the conception of depression with a range of meanings, including life stress might account for the view that depression is not serious. The view that depressive feelings can be overcome using willpower and positive thinking and do not warrant serious intervention in comparison to other mental illnesses was the view of a sample of Malaysian Muslims in Abdul Kadir and Bifulco's (2010) study who used the word 'murung' to refer to feelings of depression, stress, sadness, and disappointment. Stress, as etiology for depression, received the strongest endorsement by clergy in Ali and Milstein's (2012) study, but as that was a quantitative study, the overlayering and moral components were not accessible. In contrast, our study shows that the overlayered moral stance becomes accounted for.

The conception of depression as being equivalent to stress that results from life difficulties, however, dissuades a broader care ethic. The problem with the life-stress conception is that it undermines suffering and waters down the legitimacy of the suffering as being 'real', something that the biological conception instead achieves (Lafrance \& McKenzie-Mohr, 2013). It is for this reason that patients and clergy may become more judgmental when seeking support for adjustment disorders/life stressors. In comparison to what clergy consider to be biological depression, clergy would appear to be less empathic and may thus interact in a less sensitive manner with individuals presenting with lifestressor complaints. Rather than referring the person to a health practitioner, the cleric might suggest that the person "looks at the positive of his life" (M1).

6. zakah: "A Muslim who has money beyond a certain quantity is to pay the Zakah. It is also called the alms due or poor due" ("Key to Islamic concepts", n.d.). Zakah has rules governing its distribution. 
The problem this may lead to is that, if a person is considered to be experiencing life stress or an adjustment disorder, collaboration with western health practitioners is bypassed.

The notion of how life stressors get conceptualized according to Islamic codes has been addressed generally by similar studies. Life stressors relating to, for example, bereavement or relationship problems were categorized as the 'personal life events' explanatory model in Leavey and colleagues' (2016) study; our study picks up subtleties that show that the personal life-events dimension of mental illness is given moral judgement and lesser legitimization compared to the medicalized 'real illness' conception of depression.

Standard community-based practices could also likely contribute to the clergy in our study giving lesser legitimization to the life-stressor variety of mental illness. As a community organization, the FBO to which the clergy belong provides financial assistance to people experiencing distress due to financial difficulties; because of this built-in community support, any excessive sadness that results from typical life stressors is portrayed as unacceptable. This view is problematic in contemporary society where economic hardship and geopolitical crises do bring social problems that can lead to mental health difficulties (e.g., migration). Marital, family, and physical challenges that contribute toward lowered mood may be alleviated by pastoral strategies that are directed at teaching individuals to find positive meaning in those life's difficulties, because grief and loss as stressors are viewed as tests from Allah that allow believers to get close to Him (Sabry \& Vohra, 2013) and, on this point, the unacceptable form of depression links with the conception of depression as destiny.

The conceptualization of depression as unallowable and, therefore, transgressive implies that the symptoms are perceived to be voluntary and internal. This has links to the moralizing model of depression also found in Christian popular texts (Scrutton, 2015). Whereas Christian clergy were able to use chemical and life-stressor conceptualizations of depression together (Hankerson et al., 2013), Islamic meanings, in contrast, imbue the life-stressor variety with a moral tone that makes that type of depression come across as unallowable.

\section{Discussion}

The findings revealed an underlying nomenclature that shapes Muslim clerics' conceptualization of suffering that can be labelled as 'depression'. These conceptions are characteristic of a particular Muslim community in which these clerics offer pastoral care and social services. Even though the types overlap in their everyday engagements with the condition, the ways in which clerics 
understand cause and consequence could impact on their interventions or the help they are tasked to render.

First, depression was framed as a 'real' illness, warranting medical intervention. This variant closely resembled biomedical models with structural (brain) or biochemical factors linked to depression. Second, conceived as spiritual destiny, depression required religiously based interventions because such a condition symbolizes a test of faith and spirituality. The third type of depression was constructed as being a consequence of everyday difficulties in living. This type, even while being distinguished from transient sadness, resembles an unacceptable response to life stressors. Clergy noted this unallowable type of depression resolved once the difficulty was removed. Muslims experiencing this depression were subsequently advised to remain steadfast and optimistic because, for example, being depressed as a result of worldly challenges is unacceptable. This conception of unallowable depression has implications for the clerics' work: Working for a FBO with community goals, the clergy could revisit their conceptualizations, rather than being influenced by conceptualizations that arise from medicalization discourses of Muslim suffering.

Clergy's conceptions of depression demonstrated that the biomedical model in Islamic settings is interspersed with competing models. Even though the biomedical conception asked of the clergy in our study to refer help-seekers to a mental health practitioner if they thought themselves unable to assist, the spiritual destiny conception directed the clergy to offer support from a pastorally congruent base. The implication of this contradiction is for training sessions to interrogate such conflicts rather than only provide medical knowledge as a direct top-down transfer of information.

Mental health practitioners, trained in biomedical ideas, cannot assume that the term 'depression' is understood in the same way across different contexts. Clergy can inform mental health practitioners about the impact of religion and culture on illness beliefs; this may improve adherence to biomedical interventions. Clergy in this study recognized certain aspects of depression as a 'real' illness but indicated that religious illness beliefs cannot be bracketed. They also expressed a need for medical practitioners to acknowledge the religious contexts of their patients; this collaborative venture applies to psychologists too. Clergy within this study perceived that their opinions would be disregarded as legitimate by mental health practitioners; they believed that mental health professionals were insensitive to the religious contexts of patients. Nevertheless, the conception of depression as a 'real' illness and the accompanying rigid adherence to the medical model, particularly via notions of chemical etiology and treatment together with their own layperson's interpretation of the medical model, may be considered a barrier to referrals to mainstream healthcare workers; this can potentially inhibit opportunities for collaboration with formal healthcare systems. 
The commonality in the three conceptions of depression is the individualistic focus, whether in cause (as biomedical, as an individual's spiritual destiny, or as an individual response to stressors), or in intervention (e.g., medication, prayer, or financial assistance, respectively). The help for depression was considered to be helping the individual; a social stance, as found in Hankerson and colleagues' (2013) focus groups with African American Christian clergy, would have conceptualized collaboration as participatory and community-based. Thus, the notion of participant clergy in our study working with mainstream health practitioners seemed to imply collaboration to be a linear one-on-one interaction with health practitioners, rather than specifically creating community programs for depression like that cited in the aforementioned study (Hankerson et al., 2013). In our study, this challenge is implied by the conception of depression as unallowable sadness for, in this variety, when this conception is used, sociopolitical stressors such as gender-based violence, poverty, or crime may become undermined. This social model of illness, Scrutton (2015) argues, is disregarded by clergy, but it is this model that shows sensitivity to context and social justice.

Additionally, opportunities already exist for collaboration within the FBO structures. For example, because mental health providers are available for consultation on cases, these sessions hold potential for vibrant discussion and negotiation between divergent conceptions of depression and mental illness. In this instance, the mental health professionals need to be the point of contact for being trained about how to sensitively work with traditional community resources, rather than them being allowed to uncritically disseminate mainstream views of health and illness. In other words, psychologists and psychiatrists need to have diversity training, so they can collaborate in inclusive ways with community and religious helpers when they do enter those FBOs and communities.

Overall and remarkably, the biomedical model seemed to be the overarching conception of mental illness. Even though it appeared to be dominant in these clerics' understandings of depression, Islamic notions interspersed and even intruded into that conception. Even though this is a remarkable finding, we acknowledge that the interviewer's probing and framing of the questions in terms of depression, rather than of distress or suffering, accounted for the biomedical ideas creating an intrusive, overlayering dynamic. Thus, the limitation of this study could be related to biomedical preconceptions in the interviewing questions. In the interviews, the preference for using the medical term 'depression' may have preempted the generation of biomedical conceptions as a dominant theme. Likewise, just the cleric's knowledge of being interviewed by a mental health practitioner, as was the case in this research, may have created the condition for them to provide medically based responses, particularly if they had assumed that they were required to give 'correct' responses to the 
interview questions. Thus, we recommend that further research into conceptions of illness (including depression) with clergy, traditional healers, or even patients use neutral terminology so as not to preempt biomedical conceptions that are inherent in a (popularized) depression discourse. Future research that investigates culturally based or religiously based conceptions of mental illness should avoid such discourse in survey or interview questions. Other limitations may be related to the emphasis on sex segregation in Islamic social relations, yet our study had a female interviewer and male participants. The sex differential could have limited interviewee disclosure, or allowed dominance dynamics to come into play. Furthermore, the clergy might have found it difficult to decline the interview participation because their line manager had given their names to the interviewer in the recruitment stage. Future research should thus advertise for participation so that clergy can volunteer.

Depression discourse is rooted in medicalization. Thus, the uncritical buyin into the depression as 'real' via adopting biomedical explanations may unintentionally go against the organization's goals and mission. In other words, the individualist ideology inherent in the biomedical paradigm might overshadow religio-community values. A key recommendation for clergy, when they receive training via westernized disciplines like psychology and psychiatry, is to question and be aware of their buy-in into medical discourses. One finding that stands out is that training, which the clergy repeatedly mentioned they had received-seemingly for the discursive effect to position themselves as knowledgeable and as experts-inculcated biomedical conceptions of depression. This confirms Lafrance and McKenzie-Mohr's (2013) analytic that biomedicine's dominance is not due to top-down processes. Although bottom-up uptake is usually discursively attributed to those experiencing the emotional distress (Lafrance \& McKenzie-Mohr, 2013), our study adds to this analytic by finding that clergy themselves-actively and forthright in the interviews in our study-engaged with placing biomedicine as powerful when they conceived of depression as a 'real' illness. In other words, clergy who have received uncritical 'training' in medical models contribute to bottom-up processes by legitimizing the dominance of psychiatric nosology.

\section{REFERENCES}

76 Medicine. (n.d.). Retrieved from https://sunnah.com/bukhari/76

Abdul Kadir, N. B., \& Bifulco, A. (2010). Malaysian Muslim mothers' experience of depression and service use. Culture, Medicine, and Psychiatry, 34(3), 443-467. doi:10.1007/s11013-010-9183x

Ahmad, M. K., \& Harrison, J. (2007, October). Untapped potential: Cultural sensitivityIslamic persuasive communication in health promotion programs. Paper presented at the Global Communication and Development Conference, Shanghai, China. Retrieved from https://e space.library.uq.edu.au/view/UQ:184491 
Ahmed, S., \& Reddy, L. A. (2007). Understanding the mental health needs of American Muslims: Recommendations and considerations for practice. Journal of Multicultural Counselling and Development, 35(4), 207-218. https://doi. org/10.1002/j.2161-1912.2007.tb00061.x.

Ali, O. M., \& Milstein, G. (2012). Mental illness recognition and referral practices among imams in the United States. Journal of Muslim Mental Health, 6(2), 3-13. https://doi.org/10.3998/jmmh.10381607.0006.202.

Ali, O. M., Milstein, G., \& Marzuk, P. M. (2005). The imam's role in meeting the counselling needs of Muslim communities in the United States. Psychiatric Services, 56(2), 202-205. https://doi.org/10.1176/appi.ps.56.2.202.

Al-Shahri, M. Z., \& Al-Khenaizan, A. (2005). Palliative care for Muslim patients. The Journal of Supportive Oncology, 3(6), 432-436. Retrieved from http://www.prolifemuslims.com/PDF-word-PowerPoint/Palliative_Care_for_Muslim_Patients.pdf

Ally, Y., \& Laher, S. (2008). South African Muslim faith healers' perceptions of mental illness: Understanding, aetiology and treatment. Journal of Religion and Health, 47(1), 1-25. https://doi.org/10.1007/s10943-007-9133-2

American Psychiatric Association. (2013). Diagnostic and statistical manual of mental disorders (5th ed.). Arlington, VA: American Psychiatric Publishing. https://doi. org/10.1176/appi.books.9780890425596.

Armstrong, D. (1987). Theoretical tensions in biopsychosocial medicine. Social Science and Medicine, 25(11), 1213-1218. https://doi.org/10.1016/0277-9536(87)90368-6.

Attride-Sterling, J. (2001). Thematic networks: An analytic tool for qualitative research. Qualitative Research, 1, 285-405. https://doi.org/10.1177/148794100100307

Benning, T. B. (2015). Limitations of the biopsychosocial model in psychiatry. Advances in Medical Education and Practice, 6, 347-352. https://doi.org/10.2147/AMEP. S82937.

Braun, V., \& Clarke, V. (2006). Using thematic analysis in psychology. Qualitative Research in Psychology, 3, 77-101. https://doi.org/10.1191/1478088706qp063oa

Carnevali, R., \& Masillo, A. (2008). A brief history of psychiatry in Islamic world. Journal of the International Society for the History of Islamic Medicine (JISHIM), 6-7, 97-101. Retrieved from http://www.ishim.net/newsletter.htm

Cinnirella, M., \& Loewenthall, K. M. (1999). Religious and ethnic group influences on beliefs about mental illness: A qualitative interview study. British Journal of Medical Psychology, 72, 505-524. https://doi.org/10.1348/000711299160202.

Crossley, M. L. (2000). Rethinking health psychology. Buckingham, UK: Open University Press.

Dein, S. (2004). Working with patients with religious beliefs. Advances in Psychiatric Treatment, 10(4), 287-294. https://doi.org/10.1192/apt.10.4.287

Dejman, M., Forouzan, A. S., Assari, S., Farahani, M. A., MalekAfzali, H., Rostami, M., ... Ekblad, S. (2009). Clinicians' view of experience of assessing and following up depression among women in IR Iran. World Cultural Psychiatry Research Review, 4(2), 74-88. Retrieved from http://wcprr.org/wp/

Dejman, M., Forouzan, A. S., Assari, S., Rasoulian, M., Jazayery, A., Malekafzali, H., . . Ekblad, S. (2010). How Iranian lay people in three ethnic groups conceptualize a case of a depressed woman: An explanatory model. Ethnicity and Health, 15(5), 475-493. https://doi.org/10.1080/13557858.2010.488262.

Dwairy, M. (2006). Counselling and psychotherapy with Arabs and Muslims: A culturally sensitive approach. New York, NY: Teachers College Press.

Erdal, K., Singh, N., \& Tardif, A. (2011). Attitudes about depression and its treatment 
among mental health professionals, lay persons, immigrants, and refugees in Norway. Journal of Affective Disorders, 133(3), 481-488. https://doi.org/10.1016/j. jad.2011.04.038.

Frosh, S. (2003). Psychosocial studies and psychology: Is a critical approach emerging? Human Relations, 56(12), 1545-1567.https://doi.org/10.1177/00187267035612005.

Garcia, E. F., Duberstein, P., Paterniti, D. A., Cipri, C. S., Kravitz, R. L., \& Epstein, R. M. (2012). Feeling labeled, judged, lectured, and rejected by family and friends over depression: Cautionary results for primary care clinicians from a multi-centered, qualitative study. Family Practice, 13, 2-9. https://doi.org/10.1186/1471-2296-1364 .

Hankerson, S. H., Watson, K. T., Lukachko, A., Fullilove, M. T., \& Weissman, M. (2013). Ministers' perceptions of church-based programs to provide depression care for African Americans. Journal of Urban Health, 90(4), 685-698. https://doi. org/10.1007/s11524-013-9794-y.

Hansson, M., Chotai, J., \& Bodlund, O. (2010). Patients' beliefs about the cause of their depression. Journal of Affective Disorders, 124(1), 54-59. https://doi.org/10.1016/j. jad.2009.10.032.

Haugk, K. C. (1976). Unique contributions of churches and clergy to community mental health. Community Mental Health Journal, 12(1), 20-28. https://doi.org/10.1007/ BF01435734.

Hussain, F. A., \& Cochrane, R. (2003). Depression in South Asian women: Asian women's beliefs on causes and cures. Mental Health, Religion and Culture, 5(3), 285311. https://doi.org/10.1080/13674670210130036.

Igbinomwanhia, N. G., James, B. O., \& Omoaregba, J. O. (2013). The attitudes of clergy in Benin City, Nigeria towards persons with mental illness. African Journal of Psychiatry, 16(3), 196-200. https://doi.org/10.4314/ajpsy.v16i3.26.

Islam, J. A. (2010). The Quran and its message. Retrieved from www.quransmessage. com

Kangas, I. (2001). Making sense of depression: Perceptions of melancholia in lay narratives. Health, 5(1), 76-92. https://doi.org/10.1177/136345930100500104.

Key to Islamic concepts. (n.d.). Retrieved from http://www.islamicweb.com/begin/ key_con.htm

Khan, W. (n.d.). Difference between a Mufti and a Maulana [Online forum comment]. Retrieved from http://islamqa.org/hanafi/darululoomtt/52300

Kress, V. E. W., Eriksen, K. P., Rayle, A. D., \& Ford, S. J. W. (2005). The DSM-IV-TR and culture: Considerations for counsellors. Journal of Counselling and Development, 83, 97-105. https://doi.org/10.1002/j.1556-6678.2005.tb00584.x.

Lafrance, M. N., \& McKenzie-Mohr, S. (2013). The DSM and its lure of legitimacy. Feminism \& Psychology, 23(1), 119-140. https://doi.org/10.1177/0959353512467974.

Leavey, G., Loewenthal, K., \& King, M. (2016). Locating the social origins of mental illness: The explanatory models of mental illness among clergy from different ethnic and faith backgrounds. Journal of Religion and Health, 55(5), 1607-1622. https:// doi.org/10.1007/s10943-016-0191-1.

Lyons, A. C., \& Chamberlain, K. (2006). Health psychology: A critical introduction. Cambridge, UK: Cambridge University Press. https://doi.org/10.1017/ CBO9780511807985.

Mohamed-Kaloo, Z., \& Laher, S. (2014). Perceptions of mental illness among Muslim general practitioners in South Africa. SAMJ: South African Medical Journal, 104(5), 350-352. https://doi.org/10.7196/SAMJ.7863. 
Moj, M. (2015). The deoband madrassah movement: Countercultural trends and tendencies. London, UK: Anthem Press.

Neighbors, H. W., Musick, M, A., \& Williams, D. R. (1998). The African American minister as a source of help for serious personal crises: Bridge or barrier to mental health care. Health, Education, and Behaviour, 25, 759-777. https://doi. org/10.1177/109019819802500606.

Ogden, J. (1997). The rhetoric and reality of psychosocial theories: A challenge to biomedicine? Journal of Health Psychology, 2(1), 21-29. Retrieved from http:// epubs.surrey.ac.uk/733634/1/Ogden\%201997\%20The\%20rhetoric\%20and\%20 reality\%20of\%20psychosocial\%20theories\%20RHETHARV.pdf https://doi. org/10.1177/135910539700200103.

Okasha, A., \& Okasha, T. (2012). Religion, spirituality and the concept of mental illness. Actas Españolas de Psiquiatría, 40(Suppl 2), 73-79. Retrieved from https:// www.actaspsiquiatria.es/larevista.php

Padayachee, P., \& Laher, S. (2014). South African Hindu psychologists' perceptions of mental illness. Journal of Religion and Health, 53(2), 424-437. https://doi. org/10.1007/s10943-012-9646-1.

Padela, A. I., Killawi, A., Heisler, M., Demonner, S., \& Fetters, M. D. (2011). The role of imams in American Muslim health: Perspectives of Muslim community leaders in Southeast Michigan. Journal of Religion and Health, 50(2), 359-373. doi:10.1007/ s1094 3-010-9428-6

Patel, V. (2001). Cultural factors and international epidemiology in depression. British Medical Bulletin, 57, 33-45. https://doi.org/10.1093/bmb/57.1.33.

Pereira, B., Andrew, G., Pednekar, S., Pai, R., Pelto, P., \& Patel, V. (2007). The explanatory models of depression in low income countries: Listening to women in India. Journal of Affective Disorders, 102, 209-218. https://doi.org/10.1016/j.jad.2006.09.025.

Pridmore, S., \& Pasha, M. I. (2004). Psychiatry and Islam. Australasian Psychiatry, 12(4), 381-385. https://doi.org/10.1111/j.1440-1665.2004.02131.x.

Raskin, J. D. (2002). Constructivism in psychology: Personal construct psychology, radical constructivism, and social constructionism. In J. D. Raskin \& S. K. Bridges (Eds.), Studies in meaning: Exploring constructivist psychology (pp. 1-25). New York, NY: Pace University Press.

Rezaeian, M. (2009). Islam and suicide: A short personal communication. Journal of Death and Dying, 58(1), 77-85. https://doi.org/10.2190/OM.58.1.e.

Sabry, W. M., \& Vohra, A. (2013). Role of Islam in the management of psychiatric disorders. Indian Journal of Psychiatry, 55(Suppl S2), 205-214. Retrieved from http://www.indianjpsychiatry.org/text.asp?2013/55/6/205/105534 https://doi. org/10.4103/0019-5545.105534.

Sadeghi, H. (2011). Voice of Quran and health: A review of performed studies in Iran. Quran and Medicine, 1(Summer[En]), 33-37. Retrieved from http://quranmed. $\mathrm{com} /$ ?page $=$ home

Salem, F. (2014). Freewill, Qadar, and Kasb in the Epistle of Hasan al-Bașrī to 'Abd al-Malik. Muslim World, 104(1/2), 198-219. https://doi.org/10.1111/muwo.12039.

Sarfraz, M. A., \& Castle, D. (2002). A Muslim suicide. Australasian Psychiatry, 10(1), 48-50. https://doi.org/10.1046/j.1440-1665.2002.00392.x.

Scrutton, A. P. (2015). Is depression a sin or a disease? A critique of moralizing and medicalizing models of mental illness. Journal of Disability \& Religion, 19(4), 285311. https://doi.org/10.1080/23312521.2015.1087933

Selim, N. (2010). Cultural dimensions of depression in Bangladesh: A qualitative study 
in two villages of Matlab. Journal of Health, Population, and Nutrition, 28(1), 95106. https://doi.org/10.3329/jhpn.v28i1.4528.

Stam, H. J. (2004). A sound mind in a sound body: A critical historical analysis of health psychology. In M. Murray (Ed.), Critical health psychology (pp. 15-30). Basingstoke, UK: Palgrave Macmillan. https://doi.org/10.1007/978-0-230-21630-3_2.

Suhami, N., Muhamad, M. B., \& Krauss, S. E. (2016). Why cancer patients seek Islamic healing. Journal of Religion and Health, 55(5), 1507-1518. https://doi.org/10.1007/ s10943-015-0114-6.

Sutherland, O., Couture, S., Gaete Silva, J., Strong, T., Lamarre, A., \& Hardt, L. (2016). Social justice oriented diagnostic discussions: A discursive perspective. Journal of Feminist Family Therapy, 28(2-3), 76-99. https://doi.org/10.1080/08952833.2016. 1187532.

Vasegh, S. (2011). Cognitive therapy of religious depressed patients: Common concepts between Christianity and Islam. Journal of Cognitive Psychotherapy, 25(3), 177-188. https://doi.org/10.1891/0889-8391.25.3.177.

Wertz, F. J., Charmaz, K., McMullen, L. M., Josselson, R., Anderson, R., \& McSpadden, E. (2011). Five ways of doing qualitative analysis: phenomenological psychology, grounded theory, discourse analysis, narrative research, and intuitive inquiry. New York, NY: The Guildford Press.

Yucel, S. (2010). Prayer and healing in Islam. Izmir, Turkey: Tughra Books. 